\title{
EKSTRAKSI KUERSETIN DARI KULIT TERONG BELANDA (Solanum betaceum Cav.) MENGGUNAKAN PELARUT ETANOL DENGAN METODE MASERASI DAN SOKLETASI
}

\author{
EXTRACTION QUERCETIN OF TAMARILLO PEELS (Solanum \\ betaceum Cav.) USING ETHANOL WITH MACERATION AND \\ SOXHLETATION
}

\author{
Siswarni MZ, Yusrina Ika Putri, Rizka Rinda P* \\ Departemen Teknik Kimia, Fakultas Teknik, Universitas Sumatera Utara, \\ Jl. Almamater Kampus USU, Medan 20155, Indonesia \\ *Email :rizka.rinda11@yahoo.co.id
}

\begin{abstract}
Abstrak
Kulit terong belanda (Solanum betaceum Cav.) mengandung senyawa flavonoid yaitu kuersetin yang dapat berfungsi sebagai antioksidan. Penelitian ini bertujuan untuk mengetahui kondisi operasi yang terbaik dalam proses ekstraksi kuersetin dari kulit terong belanda sehingga diperoleh yield yang tinggi, serta dapat menunjukkan keberadaan aktivitas antioksidan secara kuantitatif. Bahan-bahan yang digunakan adalah kulit terong belanda dan etanol. Variabel berubah dalam penelitian ini adalah konsentrasi pelarut yaitu $60 \%, 70 \%, 80 \%$ dan $90 \%$ untuk maserasi dan $70 \%, 80 \%, 90 \%, 99 \%$ untuk sokletasi. Waktu ekstraksi yaitu 3 hari, 4 hari, dan 5 hari untuk maserasi, dan 3 jam, 4 jam, 5 jam untuk sokletasi. Ekstraksi dilaksanakan dengan metode maserasi dan sokletasi dengan pelarut etanol. Hasil analisis kualitatif menggunakan FTIR menunjukkan keberadaan gugus seperti keton, aril eter, hidroksil dan cincin aromatik yang menandakan keberadaan senyawa kuersetin. Hasil analisis kuantitatif menggunakan spektrofotometri UV-Vis pada variasi konsentrasi pelarut $99 \%$ dan lama ekstraksi 5 jam untuk sokletasi diperoleh yield tertinggi sebesar 0,0877 mg/g. Pada variasi konsentrasi pelarut $80 \%$ dan lama ekstraksi 5 hari untuk metode maserasi diperoleh yield tertinggi sebesar $0,0705 \mathrm{mg} / \mathrm{g}$.
\end{abstract}

Kata kunci: kulit terong belanda, kuersetin, maserasi, sokletasi, FTIR

\begin{abstract}
The tamarillo peels (Solanum betaceum Cav.) contain flavonoid compounds, quercetin that can serve as antioxidant. This research aims to determine the best condition of operation in tamarillo peels extraction process to obtain the high yield value, and to prove the presence of antioxidant activity quantitatively. The materials used this research are tamarillo peels and ethanol. The independent variables in this research were the concentration of etanol which were $60 \%, 70 \%, 80 \%$ and $90 \%$ for maceration, and $70 \%, 80 \%, 90 \%$, 99\% for soxhletation. The extraction time are 3 days, 4 days, and 5 days for maceration and 3 hours, 4 hours, 5 hours for soxhletation. Extraction is done by maceration and soxhletation. The results of the qualitative analysis using FTIR represent the presence of functional groups such as keton, arylether, hydroxyl and aromatic rings which indicates quercetin compound's presence. In quantitative analysis used Spectrofotometry UV-Vis, with the variation of $99 \%$ solvent concentration and 5 hours of extraction time for soxhletation, the highest yield value obtained 0,0877 $\mathrm{mg} / \mathrm{g}$. The variation of $80 \%$ solvent concentration and 5 days of extraction time for maceration, the highest yield value obtained $0,0705 \mathrm{mg} / \mathrm{g}$.
\end{abstract}

Keywords: tamarillo peels, quercetin, maceration, soxhletation, FTIR

\section{Pendahuluan}

Terong belanda (Solanum betaceum Cav.) merupakan buah subtropis dari famili Solanacea. Saat ini buah terong Belanda banyak dibudidayakan oleh petani di daerah Tanah Karo Sumatera Utara. Produksi terong belanda dari tahun ke tahun mengalami kenaikan, hal itu dapat dilihat dari adanya kenaikan produksi buah terong belanda di Indonesia dari tahun 2010 sebesar 482.305 ton, pada tahun 2011 sebesar 519.481 ton, dan tahun 2013 sebesar 545.646 ton [21]. Seiring dengan melimpahnya produksi terong belanda di wilayah Sumatera Utara, maka limbah kulit yang dihasilkan juga meningkat. Oleh karena itu, diperlukan penanganan terhadap limbah kulit terong belanda yangdapat dimanfaatkan diantaranya untuk ekstraksi antosianin dari kulit terong belanda [18], uji antioksidan dan kuersetin dari kulit terong belanda [5].

Kuersetin digunakan untuk sejumlah aktivitas farmakologi seperti obat diabetes, 
penyembuhan luka, dan aktivitas antioksidan [19]. Kuersetin dikategorikan sebagai flavonol yaitu salah satu dari enam subkelas senyawa flavonoid. Flavonol hadir dalam berbagai macam buah-buahan dan sayuran. Diperkirakan asupan harian manusia akan flavonol dalam kisaran 20-50 mg/hari. Dari jumlah ini, sekitar $13,82 \mathrm{mg} / \mathrm{hari}$ dalam bentuk jenis kuersetin [9].

Dikarenakan semakin tingginya kebutuhan masyarakat akan antioksidan dan belum didapatkannya hasil yang maksimal dalam ekstraksi kuersetin, maka diperlukan cara yang efektif dalam mengekstrak kuersetin yang terdapat dalam kulit terong Belanda.

\section{Teori}

Kuersetin dikategorikan sebagai flavonol, salah satu dari enam subclass senyawa flavonoid. The International Union of Pure and Applied Chemistry (IUPAC) menyebutkan nomenklatur untuk kuersetin adalah 3,3',4',5,7pentahydroxyflavanone. Kuersetin adalah aglikon. Aglikon adalah komponen bukan gula sedangkan glikon adalah komponen gula. Berbagai flavonol dibuat oleh penempatan diferensial kelompok fenolik-OH dan gula (glikon). Semua flavonol, termasuk kuersetin memiliki kesamaan yaitu 3-hydroxyflavone [9]. Rumus struktur dan padatan dari kuersetin ditunjukkan pada gambar 1 .<smiles>O=c1c(O)c(-c2ccc(O)c(O)c2)oc2cc(O)cc(O)c12</smiles>

Gambar 1. Struktur Kuersetin

Kuersetin telah banyak diteliti dalam beberapa tahun terakhir karena berbagai aktivitas farmakologi, termasuk anti kanker, anti alergi, antioksidan, dan anti-sifat inflamasi. Ini telah menunjukkan dalam pencegahan beberapa kondisi termasuk arthritis, alergi, borok, komplikasi yang berhubungan dengan diabetes, katarak, kanker, obesitas, penyakit kardiovaskular, dan infeksi mikroba [4]. Untuk mendapatkan kuersetin murni, serangkaian langkah yang melibatkan ekstraksi, hidrolisis, dan pemurnian dilakukan. Untuk ekstraksi caircair kuersetin dari sampel padat pelarut yang digunakan biasanya metanol, etanol, atau campurannya dengan air dan / atau asam hidroklorik yang paling sering digunakan [24].

Kuersetin dapat diekstraksi dengan cara maserasi [17] ataupun sokletasi [19]. Maserasi berasal dari bahasa latin Macerace berarti mengairi dan melunakan. Dasar dari maserasi adalah melarutnya bahan kandungan simplisia dari sel yang rusak, yang terbentuk pada saat penghalusan, ekstraksi (difusi) bahan kandungan dari sel yang masih utuh [22]. Sedangkan prinsip kerja metode sokletasi adalah sampel ditempatkan dalam selulosa bidal dan ditempatkan di atas pelarut mendidih. Pelarut kental maka akan menetes ke dalam sampel, pelarut mengekstrak bahan dan kemudian mengalirkan kembali ke pelarut mendidih, di mana siklus ini kemudian akan terulang. Setelah beberapa siklus selama berjam-jam, alat dibongkar dan pelarut mengandung ekstrak yang kemudian diuapkan dan meninggalkan residu untuk analisa lebih lanjut [25].

Pada penelitian ini pelarut yang digunakan adalah etanol $\left(\mathrm{C}_{2} \mathrm{H}_{5} \mathrm{OH}\right)$, karena pada prinsipnya pelarut harus memenuhi pharmaceutical grade. Sampai saat ini berlaku aturan hanya diperbolehkan air dan alkohol (etanol) serta campurannya. Jenis pelarut lain seperti heksana (hidrokarbon alifatik), toluen (hidrokarbon aromatik), kloroform, dan aseton umumnya digunakan sebagai pelarut untuk tahap separasi dan tahap pemurnian [7]. Adapun kelarutan kuersetin dalam pelarut etanol yaitu $2 \mathrm{~g} / \mathrm{L}$ [23].

\section{Metodologi Penelitian \\ Bahan dan Peralatan}

Bahan-bahan yang digunakan dalam penelitian ini adalah kulit terong belanda, etanol $\left(\mathrm{C}_{2} \mathrm{H}_{5} \mathrm{OH}\right)$, akuades $\left(\mathrm{H}_{2} \mathrm{O}\right)$, kuersetin standar, heksana $\left(\mathrm{C}_{6} \mathrm{H}_{14}\right)$, dietil eter $\left(\mathrm{C}_{4} \mathrm{H}_{10} \mathrm{O}\right)$, etil asetat $\left(\mathrm{C}_{4} \mathrm{H}_{8} \mathrm{O}_{2}\right)$, asam sulfat $\left(\mathrm{H}_{2} \mathrm{SO}_{4}\right)$, DPPH (1,1-difenil-2-pikrilhidrazil). Peralatan yang digunakan dalam penelitian ini adalah beaker glass, neraca digital, erlenmeyer, gelas ukur, corong gelas, kertas saring, alat soklet berupa labu distilasi, extraction chambers, refluks kondensor, spektrofotometer FTIR, spektrofotometer UV-Vis, rotary evaporator, pipet tetes, aluminium foil,batang pengaduk, corong pemisah, ayakan 50 mesh, oven.

\section{Prosedur Percobaan}

\section{Tahap Ekstraksi dengan Metode Maserasi}

Bahan baku yang telah dihaluskan, ditimbang dan dimasukkan ke dalam erlenmeyer kemudian dimasukkan pelarut etanol $\left(\mathrm{C}_{2} \mathrm{H}_{5} \mathrm{OH}\right)$ dengan konsentrasi $60 \%$, $70 \%, 80 \%$ dan $90 \%$ ke dalamnya dan ditutup dengan menggunakan aluminium foil selama waktu 3 hari, 4 hari dan 5 hari. 


\section{Tahap Ekstraksi dengan Metode Sokletasi}

Kulit terong belanda yang telah dihancurkan, dikeringkan dan dihaluskan, dibungkus menggunakan kertas saring yang kemudian diumpankan ke dalam alat soklet. Masukkan pelarut etanol dengan variasi konsentrasi pelarut yaitu $70 \%, 80 \%, 90 \%$ dan 99\% kedalam labu soklet. Kemudian dipanaskan dengan suhu $\pm 90^{\circ} \mathrm{C}$ selama dengan variasi waktu ekstraksi yaitu 3 jam, 4 jam, dan 5 jam.

\section{Tahap Pemurnian}

Ekstrak yang telah diperoleh dipekatkan dengan menggunakan vacum rotary evaporator pada suhu $78{ }^{\circ} \mathrm{C}$. Prosedur isolasi kuersetin ekstrak etanol terong belanda diadopsi dari Sanghavi dkk [19] yaitu ekstrak etanol kulit terong belanda diekstraksi berturut-turut dengan $50 \mathrm{ml} \mathrm{n}$-heksana (fraksi I), $50 \mathrm{ml}$ dietil eter (fraksi II), dan $50 \mathrm{ml}$ etil asetat (fraksi III) dengan menggunakan corong pemisah.Fraksi III dipekatkan dan dihidrolisis menggunakan $7 \% \mathrm{HCl}(10 \mathrm{ml} / \mathrm{g}$ residu $)$ selama $5 \mathrm{jam}$, kemudian disaring dan filtratnya diekstraksi dengan etil asetat dalam corong pisah untuk mendapatkan kuersetin. Kuersetin yang diperoleh selanjutnya dianalisa dengan menggunakan spektrofotometer UV-Vis.

\section{Prosedur Analisis}

Untuk tahap analisis kuersetin hasil penelitian, langkah awal yaitu pembuatan larutan standar flavonoid kuersetin sebagai kurva standar, yaitu membuat beberapa larutan dengan konsentrasi yaitu 0,$5 ; 1,0 ; 2,0 ; 4,0$ dan diukur absorbansinya dengan menggunakan spektrofotometer UV-Vis pada panjang gelombang $420 \mathrm{~nm}$, diperoleh nilai absorbansinya yaitu 0,$018 ; 0,060 ; 0,127$ dan 0,247 . Hasil dari pengukuran absorbansi inilah yang kemudian digunakan untuk membuat kurva standar flavonoid. Diperoleh persamaan garis untuk kurva standar flavonoid yaitu $\mathrm{y}=$ $0,07246956 \mathrm{x}-0,01613044$.

\section{Uji Kadar Total Flavonoid}

Prosedur analisis total flavonoid diadopsi dari Chang dkk [6] yaitu sebanyak 0,5 ml larutan ekstrak dilarutkan $1,5 \mathrm{~mL}$ etanol kemudian ditambahkan $0,1 \mathrm{ml} \mathrm{AlCl}_{3} 10 \% ; 0,1$ $\mathrm{mL}$ kalium asetat $1 \mathrm{M}$. Kemudian ditambahkan akuades sampai tanda, dan didiamkan 30 menit. Diukur absorbansi blangko dan sampel dengan menggunakan spektrofotometer UVVis pada panjang gelombang $432 \mathrm{~nm}$.

\section{Penentuan Yield Kuersetin}

Prosedur analisis kuantitatif ditentukan oleh massa ekstrak diadopsi dari Pan dkk [10]. Perhitungan yield dilakukan dengan nilai absorbansi yang diperoleh dikalikan dengan nilai pengenceran dan volume kemudian dibagi dengan massa sampel. Cara perhitungan adalah sebagai berikut [10]:

Yield kuersetin $(\mathrm{mg} / \mathrm{g})=\frac{\mathrm{C} \times \mathrm{N} \mathrm{x} \mathrm{V}}{\mathrm{W}}$

Dimana:

C = konsentrasi kuersetin yang diperoleh dari hasil perhitunganpersamaan regresi $(\mathrm{mg} / \mathrm{ml})$

$\mathrm{N} \quad=$ nilai pengenceran

$\mathrm{V}=$ volume ekstraksi $(\mathrm{ml})$

$\mathrm{W} \quad=$ kuantitas sampel $(\mathrm{g})$

\section{Uji Aktivitas Antioksidan}

Aktivitas antioksidan dalam ekstrak kulit terong belanda dianalisa menggunakan instrumen spektrofotometer UV dengan metode DPPH (2,2-difenil-1-pikrilhidrazil) dari Guo dkk [12]. Sebanyak $5 \mathrm{~mL}$ dari larutan uji yaitu ekstrak kulit terong belanda dicampur dengan 1 $\mathrm{mL}$ dari larutan $1 \mathrm{mM}$ DPPH dengan pelarut metanol. Larutan yang dihasilkan kemudian dibiarkan selama 30 menit sebelum dilakukan uji dengan spektrofotometri. Dideteksi absorbansinya pada panjang gelombang 517 $\mathrm{nm}$. Dihitung persentase berkurangnya warna DPPH dengan menggunakan persamaan [13]:

$\%$ Inhibisi $=1-\frac{\text { Absorbansi sampel }}{\text { Absorbansi blanko sampel }} \times 100 \%$

Dihitung nilai $\mathrm{IC}_{50}$ yang diperoleh dari persamaan regresi linier \% inhibisi DPPH terhadap konsentrasi sampel.

\section{Hasil dan Pembahasan Analisis Kualitatif}

Hasil ekstrak yang diperoleh pada kulit terong belanda berwarna kuning hingga coklat. Untuk membuktikan keberadaan dari senyawa kuersetin maka dilakukan analisis ekstrak kulit terong belanda dengan FTIR.

Menurut penelitian yang telah dilakukan oleh Aarti dkk (2012), gugus yang terdapat pada senyawa kuersetin yaitu terdiri dari ikatan gugus $\mathrm{OH}$ pada fenol $\left(3411 \mathrm{~cm}^{-1}\right), \mathrm{C}=\mathrm{O}$ keton $\left(1663,8 \mathrm{~cm}^{-1}\right), \mathrm{C}=\mathrm{C}$ cincin aromatis $(1608,8$ $\left.\mathrm{cm}^{-1}\right)$, regangan aril C-O $\left(1265 \mathrm{~cm}^{-1}\right)$, regangan C-O-C pada keton $\left(1167 \mathrm{~cm}^{-1}\right)$ dan $\mathrm{C}-\mathrm{H}$ cincin aromatis $\left(940,6 ; 821,4 ; 677 ; 602,3 \mathrm{~cm}^{-1}\right)$ [1]. Data vibrasi hasil analisis ekstrak kulit terong belanda dapat dilihat pada tabel 1 . 
Tabel 1. Data Vibrasi Hasil Analisis FT-IR

\begin{tabular}{|c|c|c|c|}
\hline \multirow{2}{*}{$\begin{array}{c}\text { Gugus } \\
\text { Fungsinya }\end{array}$} & $\begin{array}{c}\text { Standar } \\
{[11]}\end{array}$ & $\begin{array}{c}\text { Hasil } \\
\text { Penelitian } \\
\text { dengan } \\
\text { Sokletasi }\end{array}$ & $\begin{array}{c}\text { Hasil } \\
\text { Penelitian } \\
\text { dengan } \\
\text { Maserasi }\end{array}$ \\
\hline OH & $3570-3200$ & 3462,22 & 3413,13 \\
\hline $\mathrm{C}=\mathrm{O}$ & $1725-1700$ & 1723,09 & 1712,39 \\
\hline Aromatik, & $1615-1450$ & 1447,18 & - \\
C=C & $1410-1310$ & 1373,97 & 1374,55 \\
\hline Fenol,OH & $1270-1230$ & 1237,21 & 1238,89 \\
\hline $\mathrm{C}-\mathrm{O}$ & $1150-1050$ & 1094,67 & 1092,43 \\
\hline $\mathrm{C}-\mathrm{O}-\mathrm{C}$ & & 938,$31 ;$ & 879,$0 ;$ \\
\hline & & 879,$35 ;$ & 848,$0 ;$ \\
Aromatik & $900-670$ & 847,$60 ;$ & 786,82 \\
C-H & & 787,66 & \\
\hline
\end{tabular}

Dari tabel 1 dapat dilihat bahwa gugus gugus yang seharusnya terdapat pada kuersetin telah ditemukan juga pada sampel ekstrak kulit terong belanda. Namun pada hasil maserasi, vibrasi yang terbaca pada hasil analisis ekstrak kulit terong belanda kurang jelas untuk menunjukkan gugus $\mathrm{C}=\mathrm{C}$ aromatik yang seharusnya terbaca jelas untuk senyawa kuersetin. Hal ini disebabkan karena proses pemurnian yang tidak terjadi secara sempurna, sehingga masih adanya zat - zat lain yang tidak dapat dipisahkan secara sempurna, yang kemudian menutupi kehadiran dari gugus cincin aromatis yang ada dalam ekstrak kulit terong belanda.

\section{Analisis Kuantitatif \\ Pengaruh Konsentrasi Pelarut Terhadap Yield Kuersetin}

Konsentrasi pelarut merupakan variabel yang berhubungan langsung dengan hasil ekstrak yang diperoleh selama proses ekstraksi. Beberapa penelitian menyatakan penambahan air pada pelarut berpengaruh pada hasil flavonoid seperti kuersetin [15]. Pengaruh konsentrasi pelarut terhadap yield dapat dilihat pada gambar 2 dan 3 .

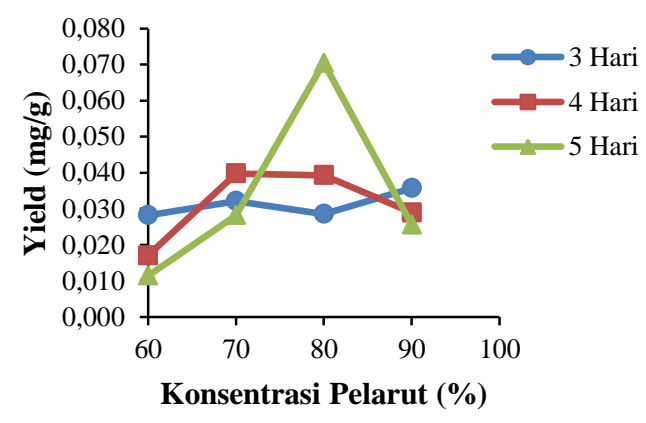

Gambar 2. Pengaruh Konsentrasi Pelarut Terhadap Yield Kuersetin Pada Metode Maserasi
Pada gambar 2 dapat dilihat bahwa yield kuersetin yang diperoleh secara umum semakin meningkat seiring dengan konsentrasi pelarut etanol yang semakin besar. Yield kuersetin yang diperoleh dari proses ekstraksi dengan menggunakan etanol $80 \%$ menunjukkan perbedaan yang besar pada berbagai variasi waktu. Hal ini menunjukkan bahwa sedikit perbedaan konsentrasi pelarut yang digunakan, dapat mempengaruhi yield kuersetin yang diperoleh.



Gambar 3. Pengaruh Konsentrasi Pelarut Terhadap Yield Kuersetin Pada Metode Sokletasi

Dari gambar 3 secara keseluruhan terlihat bahwa dengan meningkatnya konsentrasi etanol pada pelarut meningkatkan yield yang diperoleh. Yield terbesar diperoleh pada konsentrasi etanol 90\% dengan perolehan yield rata-rata sebesar $0,0618 \mathrm{mg} / \mathrm{g}$ dan yield terendah dengan perolehan rata-rata sebesar $0,0426 \mathrm{mg} / \mathrm{g}$ pada konsentrasi etanol $99 \%$.

Yield kuersetin meningkat dengan meningkatnya konsentrasi etanol. Wang dkk (2014) menyatakan bahwa ketika konsentrasi etanol mencapai maksimal, yield menurun, hal ini di interprestasikan sebagai kenaikan kelarutan kuersetin dengan meningkatnya konsentrasi etanol. Namun saat konsentrasi etanol lebih tinggi dari maksimum, laju ekstraksi dari kuersetin menurun secara bertahap [26].

Campuran etanol dengan air dapat meningkatkan jumlah senyawa fenolik glikosida yang terekstrak, dimana zat ini merupakan jenis senyawa yang larut dalam air. Selain itu, dengan adanya penambahan air ke dalam pelarut yang digunakan dapat memperbesar jaringan pada tumbuhan (sampel) tersebut sehingga kontak luas permukaan antara jaringan tumbuhan (sampel) dengan pelarut akan semakin besar [14]. 
Pengaruh Waktu Ekstraksi Terhadap Yield Kuersetin

Lama waktu ekstraksi merupakan variabel yang berhubungan langsung dengan hasil ekstrak yang diperoleh selama proses ekstraksi. Pada gambar 4 dapat dilihat pengaruh waktu ekstraksi terhadap yield kuersetin yang diperoleh.

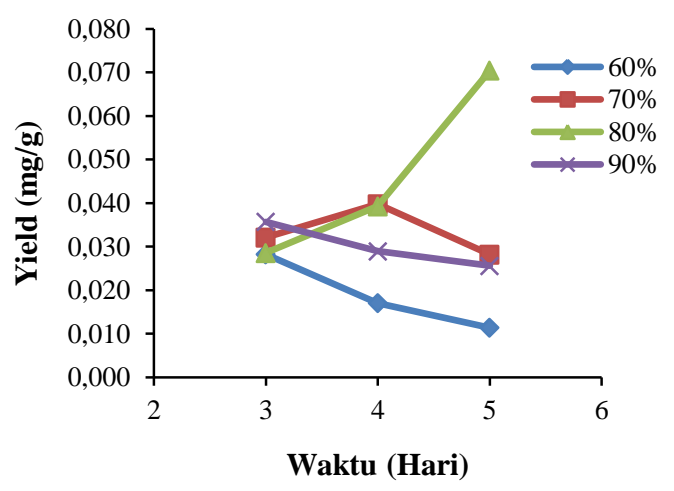

Gambar 4. Pengaruh Waktu Ekstraksi Terhadap Yield Kuersetin Pada Metode Maserasi

Pada gambar 4 dapat dilihat bahwa yield kuersetin yang diperoleh secara umum semakin meningkat seiring dengan waktu ekstraksi yang semakin lama. Secara teori bahwa semakin lama proses ekstraksi berlangsung, kontak antara sampel dan pelarut juga semakin lama sehingga kemampuan pelarut untuk mengekstrak senyawa dalam sampel akan lebih maksimal [3].

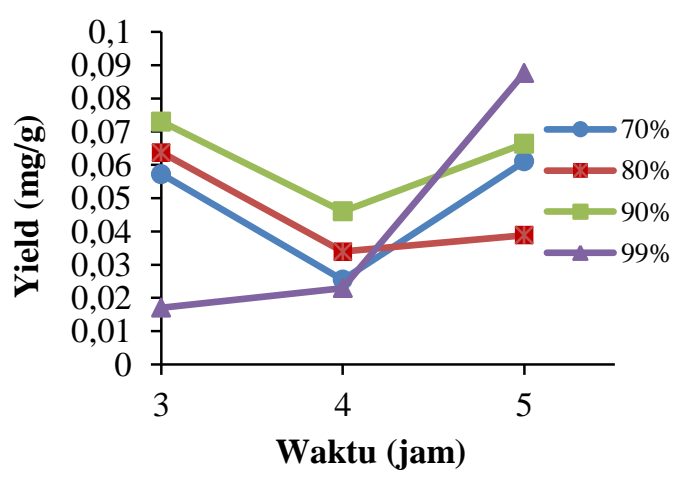

Gambar 5. Pengaruh Waktu Ekstraksi Terhadap Yield Kuersetin Pada Metode Sokletasi

Dari gambar 5 secara keseluruhan terlihat bahwa meningkatnya waktu ekstraksi menurunkan yield yang diperoleh. Namun terjadi kenaikan pada saat telah terjadinya penurunan. Yield terbesar diperoleh pada waktu ekstraksi 5 jam dengan perolehan yield rata-rata sebesar $0,0635 \mathrm{mg} / \mathrm{g}$ dan yield terendah dengan perolehan rata-rata sebesar $0,0321 \mathrm{mg} / \mathrm{g}$.

Terjadi penurunan yield dari waktu ekstraksi 3 jam menuju 4 jam. Menurut Chew dkk (2011) mengikuti hukum kedua Fick dari difusi yang memprediksi bahwa keseimbangan akhir antara konsentrasi zat terlarut dalam matriks padat (matriks tanaman) dan dalam larutan curah (pelarut) mungkin dicapai setelah waktu tertentu, yang mengarah ke perlambatan dalam hasil ekstraksi [14].

\section{Uji Aktivitas Antioksidan}

Pengujian aktivitas antioksidan ekstrak dilakukan dengan menggunakan metode DPPH. Metode ini paling umum digunakan karena merupakan metode yang sederhana, cepat serta bahan kimia dan sampel yang digunakan hanya sedikit.

Uji aktivitas antioksidan secara kuantitatif dinyatakan dalam $\mathrm{IC}_{50}$ (Inhibition Concentration) yaitu besarnya konsentrasi sampel yang dibutuhkan untuk menghambat $50 \%$ radikal bebas. Daya aktivitas antioksidan berdasarkan nilai $\mathrm{IC}_{50}$ dapat dibagi menjadi beberapa kategori, yaitu jika $\mathrm{IC}_{50}<50$ ppm, maka daya antioksidan sangat kuat, $\mathrm{IC}_{50} 50-$ 100 ppm daya antioksidan kuat, $\mathrm{IC}_{50} 101-150$ ppm daya antioksidan sedang, $\mathrm{IC}_{50} 150-200$ ppm daya antioksidan lemah dan $\mathrm{IC}_{50}>200$ ppm daya antioksidan sangat lemah [8]. Semakin kecil nilai $\mathrm{IC}_{50}$ suatu senyawa maka dapat dikatakan bahwa semakin efektif senyawa tersebut sebagai antioksidan [11]. Data nilai $\mathrm{IC}_{50}$ sampel ekstrak kulit terong belanda pada metode maserasi dan sokletasi dapat dilihat pada tabel 2 dan tabel 3 berikut.

Tabel 2. Data Nilai IC $_{50}$ Sampel Ekstrak Kulit Terong Belanda Pada Metode Maserasi

\begin{tabular}{|c|c|c|c|}
\hline No & $\begin{array}{c}\text { Konsentrasi } \\
\text { Pelarut (\%) }\end{array}$ & $\begin{array}{c}\text { Waktu } \\
\text { (Hari) }\end{array}$ & $\begin{array}{c}\text { Aktivitas } \\
\text { Antioksidan } \\
\mathrm{IC}_{50}(\mathrm{ppm})\end{array}$ \\
\hline 1 & 70 & \multirow{2}{*}{4} & 2,78 \\
2 & 90 & & 6,98 \\
\hline
\end{tabular}

Tabel 3. Data Nilai IC $_{50}$ Sampel Ekstrak Kulit Terong Belanda Pada Metode Sokletasi

\begin{tabular}{|c|c|c|c|}
\hline No & $\begin{array}{c}\text { Konsentrasi } \\
\text { Pelarut (\%) }\end{array}$ & $\begin{array}{c}\text { Waktu } \\
(\mathrm{jam})\end{array}$ & $\begin{array}{c}\text { Aktivitas } \\
\text { Antioksidan } \\
\mathrm{IC}_{50}(\mathrm{ppm})\end{array}$ \\
\hline 1 & 80 & \multirow{2}{*}{4} & 6,56 \\
\hline 2 & 99 & & 9,37 \\
\end{tabular}


Senyawa golongan fenol, seperti flavonoid merupakan senyawa utama paling kuat yang berperan sebagai antioksidan [8]. Kemampuan antioksidan sebagai penangkap radikal bebas dikaitkan dengan kemampuan antioksidan tersebut sebagai donor proton. Jumlah proton hidrogen yang dapat didonorkan dipengaruhi jumlah dan posisi gugus hidroksil aromatik atau hidroksil dari komponen fenolik. Semakin banyak gugus hidroksil aromatik, kemampuan penghambatan reaksi berantai pada proses oksidasi semakin efektif dengan cara mendonorkan atom hidrogen atau berperan sebagai akseptor radikal bebas [2].

\section{Kesimpulan}

Pelarut etanol dapat digunakan untuk mengekstraksi senyawa kuersetin yang terdapat dalam kulit terong belanda. Dari hasil analisa FTIR terhadap hasil ektraksi terdapat kandungan gugus keton, aril eter, hidroksil dan cincin aromatis yang menunjukkan keberadaan senyawa kuersetin. Yield hasil ekstraksi kuersetin tertinggi diperoleh pada variasi konsentrasi pelarut etanol $80 \%$ dan waktu ekstraksi 5 hari sebesar $0,0705 \mathrm{mg} / \mathrm{g}$ untuk maserasi dan diperoleh $0,0877 \mathrm{mg} / \mathrm{g}$ pada variasi konsentrasi pelarut $99 \%$ dan lama ekstraksi 5 jam untuk sokletasi.

\section{Daftar Pustaka}

[1] A. Chourasiya, A. Upadhayay, R. N. Shukla, To Asses Isolation of Quercetin From The Leaves of Azadirachta indica and Antidiabetic Study of The Crude Extracts,Journal of Pharmaceutical and Biomedical Sciences, 25(25) 2012 : hal. 179.

[2] A. T. Septiana, A. Asnani, Aktivitas Antioksidan Ekstrak Rumput Laut Sargassum duplication,Jurnal Teknologi Pertanian, 14 (2) 2013 : hal. 80.

[3] A. Yulianingtyas, B. Kusmartono, Optimasi Volume Pelarut dan Waktu Maserasi Pengambilan Flavonoid Daun Belimbing Wuluh (Averrhoa bilimbi L.),Jurnal Teknik Kimia, 10(2) 2016 : hal. 58.

[4] B. E. Kilfoyle, D. Kaushik, J.L. Terebetski, S. Bose, and B. B. MichniakKohn, Formulating, Packaging, And Marketing Of Natural Cosmetic Products Chapter 14 : The Use Of Quercetin And Curcumin In Skin are Consumer Products (New Jersey:) John Wiley \& Sons, Inc., Hoboken, New Jersey,

[5] C. Vasco, J. Avila, J. Ruales, U. Svanberg, and A. Kamal-Eldin, Physical and chemical characteristics of goldenyellow and purple-red varieties of tamarillo fruit (Solanum betaceum Cav.),International Journal of Food Sciences and Nutrition, 60(7) 2009 : hal $278-288$.

[6] C.C Chang, M. Yang, H. Wen, J. Chern, Estimation of total flavonoid content in propolis by two complementary colorimetric methods, Journal Food Drug Anal, 10(3):178-82, 2002

[7] Departemen Kesehatan RI. "Parameter Standar Umum Ekstrak Tumbuhan Obat" Direktorat Jenderal Pengawasan Obat dan Makanan, 9, 2000

[8] F. Firdiyani, T. W. Agustini, W.. F. Ma'ruf, Ekstraksi Senyawa Bioaktif Sebagai Antioksidan Alami Spirulina plantesis Segar dengan Pelarut yang Berbeda,JPHPI, 18(1) 2015 :hal. 29.

[9] G. S. Kelly, Quercetin Alternative Medicine Review, 16(2), 2011

[10] G. Pan, G. Yu, C. Zhu, J. Qiao, Optimization of Ultrasound-assisted Extraction (UAE) of flavonoids compounds (FC) from Hawthorn Seed (HS),Ultrasonics Sonochemistry, 19, 2012

[11] I. J. Putri, Fauziyah dan Elfita, Aktivitas Antioksidan Daun dan Biji Buah Nipah (Nypa fruticans) Asal Pesisir Banyuasin Sumatera Selatan dengan Metode DPPH, Maspari Journal, 5(1) 2015 : hal. 17.

[12] J. T. Guo,.et al. Antioxidant Properties of The Extracts From Differents Parts of Broccoli in Taiwan, Journal Food Drug Analysis, 9(2) 2001 : hal 96 - 101.

[13] J. Coates, Interpretation of Infrared Spectra, a Practical Approach, Encyclopedia of Analyrical Chemistry, 2007, hal. $5-8$.

[14] K. K. Chew, M.Z Khoo, S. Y. Ng, Y. Y. Thoo, Aida, W.M. Wan, Ho, C.W, Effect of ethanol concentration, extraction time and extraction temperature on the recovery of phenolic compounds and antioxidant capacity of Orthosiphon stamineus extract International Food Research Journal, 18 (4), 2011.

[15] Mahmiah, Isolation and Identification Flavonoid Compound From The Stem Bark of Saccopetalum horsfieldii Benn Indo. J. Chem., 6(3), 2006, hal 312-315.

[16] M. C. Tan, C. P. Tan, C. W. Ho, Effect of Extraction Solvent System, Time and Temperature on Total Phenolic Content of Henna (Lawsonia inermis) Stems, 
International Food Research Journal, 20 (6) 2013 : hal. 3118.

[17] M. F. Daud, E. R. Sadiyah, E.Rismawati, Pengaruh Perbedaan Metode Ekstraksi Terhadap Aktivitas Antioksidan Ekstrak Etanol Daun Jambu Biji (Psidium guajava L.) Berdaging Buah Putih, Prosiding SNaPP Sains, Teknologi dan Kesehatan, 2(1) 2011 : hal $55-56$.

[18] N. H. Hurtado, et al., Colour, pH stability and antioxidant activity of anthocyanin rutinosides isolated from tamarillo fruit (Solanum betaceum Cav.),Food Chemistry, 117, 2009, hal 88-93.

[19] N. Sanghavi, R. Srivastava, Y.Malode, Isolation And Identification of The Flavonoid Quercetin From Tridax Procumbens Linn. International Journal of Pharmaceutical Sciences and Research, 5(4), hal 1458.

[20] P. N. Rahardjo, Studi Banding Teknologi Pengolahan Limbah Cair Pabrik Kelapa Sawit, Jurnal Teknologi Lingkungan, Volume 10 No. 1, hal : 09-18, 2009.

[21] Rosdiana, E. Julianti, L. N. Limbong, Pemberian Ethepon Sebagai Bahan Perangsang Pematangan Pada Buah Terung Belanda Dengan Dua Tingkat Kematangan,Jurnal Rekayasa Pangan dan Pertanian, 2(2), 2014

[22] R. Voight, Buku Pelajaran Teknologi Farmasi (Yogyakarta: Universitas Gajah Mada Press, 1994), hal. 577 - 578.

[23] S. F. Nabavi, G. L. Russo, M. Daglia, S. M. Nabavi, Role of Quercetin as an Alternative for Obesity Treatment: You are What You Eat, Food Chemistry, 2015, hal. 7 .

[24] S. G. Dmitrienko, V. A. Kudrinskaya, dan V. V. Apyari, Methods of Extraction, Preconcentration, and Determination of Quercetin, Journal of Analytical Chemistry, 67 (4), hal. 299-311, 2012.

[25] S. Anderson, Chapter 2 Soxtec: It's Principles And Applications. Oil Extraction and Analysis: Critical Issues and Comparative Studies, AOCS Press, 2004.

[26] X.H. Wang, J.T. Dai, J.P. Wang and X.H. $\mathrm{Wu}$, Enhacement Extraction of Quercetin from Suaeda glauca Bge. Using Ionic Liquid as Solvent, Asian Journal of Chemistry, 26 (4), 2014.

[27] Y. G. Fanny, Pengaruh Pelarut Terhadap Karakteristik Ekstrak Daun Senduduk (Melastoma malabathricum, L), Skripsi, Jurusan Teknologi Hasil Pertanian.
Fakultas Teknologi Pertanian Universitas Andalas, Padang, 2014, hal 1. 